\title{
Interação do tratamento de sementes e da mistura em tanque de herbicidas na seletividade para $o$ arroz irrigado
}

\author{
Interaction of seed treatment and herbicide tank mixture in paddy rice selectivity
}

\author{
Julio Marcos Catoni ${ }^{1}$, Antonio Mendes de Oliveira Neto ${ }^{2 \star}$, Cristiano Riscarolli ${ }^{1}$, Naiara Guerra ${ }^{3}$ \\ ${ }^{1}$ Instituto Federal Catarinense, Rio do Sul, SC, Brasil. \\ 2Universidade do Estado de Santa Catarina, Lages, SC, Brasil. *Autor para correspondência: am.oliveiraneto@gmail.com. \\ ${ }^{3}$ Universidade Federal de Santa Catarina, Curitibanos, SC, Brasil.
}

Submissão: 17/12/2018 / Aceite: 10/12/2019

\begin{abstract}
RESUMO
A elevada fitointoxicação após a aplicação de herbicidas tem se tornado cada vez mais frequentes em função da mistura em tanque de herbicidas praticada a campo, pressionadas pelo aumento do espectro de controle e pelo avanço da resistência de plantas daninhas a herbicidas. Objetivou-se, neste trabalho avaliar a interação do tratamento de sementes com uma formulação comercial de fungicida e inseticida com a aplicação de mistura em tanque de herbicidas no arroz irrigado, cultivado no sistema prégerminado, na região do Alto Vale do Itajaí, SC. O experimento foi conduzido em uma área comercial sistematizada para o sistema pré-germinado, com a cultivar SCS $121 \mathrm{CL}$. O delineamento experimental utilizado foi o de blocos casualizados com tratamentos arranjados em esquema fatorial $4 \times 2$, com quatro repetições. Avaliou-se dois níveis de tratamento de sementes (com ou sem) e quatro tratamentos herbicidas (sem herbicida, [imazapyr + imazapic] + bentazon, [imazapyr + imazapic] + saflufenacil e [imazapyr + imazapic] + bentazon + saflufenacil). A primeira aplicação foi realizada em $\mathrm{V}_{2}$ apenas com a mistura comercial de [imazapyr + imazapic] e a segunda aplicação foi realizada em $V_{3}$ com tratamentos. As variáveis avaliadas foram fitointoxicação, número de plantas por metro quadrado, número de perfilhos por planta, número de panículas por metro quadrado, número de grãos por panícula, massa da panícula, esterilidade de espiguetas, massa de mil grãos e produtividade de grãos. Concluiu-se que o tratamento de sementes com a mistura formulada de fungicida e inseticida reduziu a fitointoxicação da mistura de [imazapyr + imazapic] + bentazon + saflufenacil. Além disso, houve superioridade numérica nos componentes de rendimento e na produtividade de grãos com o tratamento de semente.
\end{abstract}

PALAVRAS-CHAVE: fitointoxicação, Oryza sativa, pré-germinado, SCS $121 \mathrm{CL}$.

\begin{abstract}
Increased phytointoxication level after herbicide tank mixtures has been frequent in field conditions, pressured by the improvement of the control spectrum and the advance of herbicide-resistant biotypes. The objective of this work was to assess the interaction of seed treatment with a commercial formulation of fungicide and insecticide with herbicide tank mixture after the application in paddy rice, in the pregerminated seed system, in the Alto Vale do Itajaí region. To carry out the experiment in the commercial field prepared for the pre-germinated seed system, sowing SCS $121 \mathrm{CL}$ cultivar. The experimental design was a block completely randomized with treatments organized in factorial design $4 \times 2$, with four replications. We assessed two levels seed treatment (with or without) and four herbicide treatments (without herbicide, [imazapyr + imazapic] + bentazon, [imazapyr + imazapic] + saflufenacil, and [imazapyr + imazapic] + bentazon + saflufenacil). The first spray was carried out in $\mathrm{V}_{2}$ only with the commercial mixture of [imazapyr + imazapic], and the second spray was carried out in $V_{3}$ with treatments. The variables assessed were phytointoxication, number of plants per square meter, number of tillers by plant, number of panicles per square meter, number of grains per panicle, panicle weight, spikelet sterility, thousand grains weight, and grain yield. We concluded that seed treatment with a formulated mixture of insecticide and fungicide reduced the phytointoxication of saflufenacil mixing treatments. Moreover, there was numeric superiority of yield compounds and grain yield with seed treatment.
\end{abstract}

KEYWORDS: phytointoxication, Oryza sativa, pre-germinated, SCS $121 \mathrm{CL}$. 


\section{INTRODUÇÃO}

O arroz é um dos alimentos mais comuns na nutrição humana, sendo cultivado em diversos países e o segundo cereal mais produzido no mundo (FAO 2019). O Brasil atualmente produz em torno de 12 milhões de toneladas do grão, onde cerca de 10\% é produzido em Santa Catarina (SOSBAI 2016). O estado está dividido em quatro sub-regiões produtoras, sendo na região do Alto Vale do Itajaí onde se alcança as maiores produtividades de arroz em casca, com média superior a $8.000 \mathrm{~kg} \mathrm{ha}^{-1}$. O cultivo do arroz no estado é predominantemente irrigado, com predomínio do sistema pré-germinado, ocupando aproximadamente $80 \%$ da área. Os $20 \%$ restantes são conduzidos no sistema de semeadura convencional ou cultivo mínimo, com semeadura em solo drenado.

No cultivo do arroz, entre outros desafios, o controle de plantas daninhas é importante para manutenção do potencial produtivo, já que o manejo das plantas indesejadas pode acarretar em grandes perdas de produtividade, decorrentes da elevada capacidade destas competirem por água, luz e nutriente com a cultura de interesse (BERTUCCl et al. 2019).

Nesse contexto, a sagitária (Sagittaria montevidensis) tem se tornado uma planta daninha de difícil controle nas lavouras arrozeiras, principalmente nas áreas de cultivo pré-germinado, onde basicamente utiliza-se o controle químico para conter as infestações dessa espécie. Como resultado, foram identificados diversos biótipos de sagitária resistentes a herbicidas inibidores da enzima acetolactato sintase (ALS EC 4.1.3.18.) (MEROTTO JUNIOR et al. 2010, HAVERROTH et al. 2017). Recentemente, foram identificadas populações com resistência múltipla a inibidores da ALS e do fotossistema II em Santa Catarina (MOURA et al. 2015).

A ocorrência de biótipos de sagitária com resistência múltipla ocasionou o aumento no uso do herbicida saflufenacil, bem como da mistura em tanque de herbicidas. Todavia, o avanço dessa prática acabou promovendo a intensificação dos sintomas de fitointoxicação em plantas de arroz irrigado. Nessas condições é frequente a visualização inicial de sintomas como manchas verde escuras nas folhas, que posteriormente progridem para manchas necróticas e secamento das folhas (SOLTANI et al. 2009). Estes sintomas são o resultado do estresse oxidativo iniciado por espécies reativas de oxigênio (EROs), como os radicais superóxido $\left(\mathrm{O}_{2}-\right)$, radicais hidroxila $(\mathrm{OH}-)$, peróxido de hidrogênio $\left(\mathrm{H}_{2} \mathrm{O}_{2}\right)$ e oxigênio singleto $\left({ }^{1} \mathrm{O}_{2}\right)$ (GILL \& TUTEJA 2010). As EROs reagem com lipídios formadores de membranas, causando a peroxidação lipídica (TAKANO et al. 2019).

O saflufenacil pertence ao grupo químico das Pirimidinadionas, atua inibindo a enzima Protoporfirinogênio IX oxidase (Protox EC 1.3.3.4), a absorção ocorre tanto pelas raízes quanto pelas folhas, e a translocação ocorre principalmente via xilema, pois possui baixa mobilidade no floema (LIEBL et al. 2008, SOLTANI et al. 2009, KNEZEVIC et al. 2010). A enzima Protox é encontrada em cloroplastos e mitocôndrias de células vegetais, atua na rota de biossíntese das clorofilas e grupos heme, (KNEZEVIC et al. 2009 e 2010, DAYAN \& WATSON 2011, MATZENBACHER et al. 2014) catalisando a oxidação de protoporfirinogênio IX para protoporfirina IX.

Com a inibição desta enzima ocorre o acúmulo de protoporfirinogênio IX no cloroplasto, em consequência deste acúmulo há difusão deste composto para o citosol, onde o protoporfirinogênio IX também é oxidado a protoporfirina IX, porém no citosol as enzimas da via de biossíntese da clorofila não estão disponíveis, acarretando no acúmulo de protoporfirina IX (GEOFFROY et al. 2002). A protoporfirina IX acumulada interage com a luz e o oxigênio molecular gerando EROs, como o oxigênio singlet, que provocam a peroxidação lipídica e danos às membranas. Com isso ocorre uma rápida perda da integridade das membranas, ocasionando o extravasamento celular, necrose dos tecidos e consequentemente, a morte da planta (KNEZEVIC et al. 2009, GROSSMANN et al. 2011).

Os sintomas de fitointoxicação observados em plantas tolerantes deve-se ao dano nas membranas celulares por peroxidação lipídica, resultando em extravasamento do conteúdo celular para o meio e necrose dos tecidos (KRUSE et al. 2006). Além dos efeitos descritos, as EROs podem reagir com inúmeros componentes celulares, causando reações de oxidação em cascata que resultam na inativação de enzimas, degradação de proteínas, danos ao DNA e pigmentos celulares (GAO et al. 2019).

Em suma, o problema de fitointoxicação causada nas lavouras de interesse tem se tornado cada vez mais frequentes em função das misturas de herbicidas praticadas a campo, sempre pressionadas pela dificuldade no controle e pela quantidade de plantas resistentes ou tolerantes a herbicidas de diferentes mecanismos de ação.

A mitigação da elevada fitointoxicação promovida pelo estresse oxidativo resultante de tratamentos herbicidas pode ser conseguida através de medidas que favoreçam a síntese de compostos antioxidantes, como as enzimas superóxido dismutase (SOD), ascorbatoperoxidase (APX), glutationaperoxidase (GPX), 
guaiacol peroxidase (GPOX) e catalase (CAT); também inclui aqueles compostos não enzimáticos, como tocoferol (vitamina E), caroteno, ascorbato (vitamina C), e glutationa (GSH) (GAO et al. 2019). Neste sentido, o tratamento de sementes com fungicidas do grupo químico das estrobilurinas poderia ser uma alternativa a ser empregada (KANUNGO \& JOSHI 2014). Já foi elucidado que o fungicida pyraclostrobin promove um incremento na atividade foliar da enzima peroxidase, com incremento iniciando aos cinco dias após o tratamento e persistindo por quatro semanas, contribuindo assim com a tolerância ao estresse oxidativo (KÖEHLE et al. 2003).

Além disso, observou-se efeito direto em processos fisiológicos de plantas não infectadas ou ameaçadas por patógenos, sendo esta característica denominada de efeito aditivo ou efeito fisiológico positivo (VENANCIO et al. 2004, LIMA et al. 2009). Pyraclostrobin proporciona à planta melhor desenvolvimento, promovendo mudanças fisiológicas que permitem: redução do estresse, melhor utilização de $\mathrm{CO}_{2}$, maior teor de clorofila, redução da produção de etileno permitindo maior duração da vida útil das folhas, e incremento na atividade da enzima nitrato-redutase (JABS 2004).

A hipótese inicial deste trabalho foi que o tratamento de sementes com estrobilurina seria uma alternativa para diminuição da fitointoxicação causada por misturas envolvendo o herbicida saflufenacil, e assim, objetivou-se, neste trabalho avaliar a interação do tratamento de sementes com uma formulação comercial de fungicida e inseticida com a aplicação de mistura em tanque de herbicidas no arroz irrigado, cultivado no sistema pré-germinado.

\section{MATERIAL E MÉTODOS}

O experimento foi realizado em lavoura comercial de arroz irrigado, localizada no município de Taió, SC, coordenadas geográficas 27¹0'33"de latitude Sul, 4957'29"de longitude Oeste, em área de Cambissolo Háplico sistematizada para o cultivo de arroz irrigado há 15 anos. O preparo do solo iniciou com o manejo de palhada na entressafra, na época de implantação o solo foi preparado com enxada rotativa para formação da lama, posteriormente realizado o alisamento e nivelamento da área deixando o leito de semeadura preparado para o sistema pré-germinado.

$O$ delineamento experimental utilizado foi de blocos casualizados com tratamentos arranjados em esquema fatorial $4 \times 2$, com quatro repetições. Avaliou-se a interação de dois níveis de tratamento de sementes (com ou sem tratamento de sementes com pyraclostrobin + thiophanate-methyl + fipronil a $2,5 \mathrm{~mL}$ $\mathrm{kg}^{-1}$ de semente) e quatro tratamentos herbicidas (sem herbicida, [imazapyr + imazapic] + bentazon, [imazapyr + imazapic] + saflufenacil e [imazapyr + imazapic] + bentazon + saflufenacil). Os herbicidas foram aplicados seguindo as recomendações técnicas do sistema Clearfield ${ }^{\circledR}$, sendo a primeira aplicação realizada dia 14/10/2017 em $V_{2}$, apenas com herbicida [imazapyr + imazapic] e na segunda aplicação, realizada dia 27/10/2017 em $V_{3}$, aplicou-se os tratamentos herbicida. A escala fenológica adotada foi a de COUNCE et al. (2000).

Cada unidade experimental tinha área total de $15 \mathrm{~m}^{2}(3 \times 5 \mathrm{~m})$ e área útil de $8 \mathrm{~m}^{2}(2 \times 4 \mathrm{~m})$. As parcelas que receberam tratamento de sementes foram isoladas, com o auxílio de chapas flexíveis de PVC, para evitar a contaminação das parcelas não tratadas. Utilizou-se os herbicidas comerciais Kifix ${ }^{\circledR}(73,5+$ $24,5 \mathrm{~g} \mathrm{ha}^{-1}$ de ingrediente ativo (i.a.)), Basagran $600^{\circledR}\left(1.200 \mathrm{~g} \mathrm{ha}^{-1}\right.$ de i.a.) e $\mathrm{Heat}^{\circledR}\left(70 \mathrm{~g} \mathrm{ha}^{-1}\right.$ de i.a.) para os ingredientes ativos [imazapyr + imazapic], bentazon e saflufenacil, respectivamente. Em todas as aplicações de herbicidas o adjuvante utilizado foi Dash ${ }^{\oplus}$ na dose de $0,5 \mathrm{~L} \mathrm{ha}^{-1}$.

As adubações foram baseadas na interpretação da análise de solo da área e calculadas conforme o manual de Recomendações Técnicas da Pesquisa para o Sul do Brasil da Sociedade Sul-Brasileira de Arroz Irrigado (SOSBAI 2016), resultando em $70 \mathrm{~kg} \mathrm{ha}^{-1}$ de $\mathrm{P}_{2} \mathrm{O}_{5}, 70 \mathrm{~kg} \mathrm{ha}^{-1}$ de $\mathrm{K}_{2} \mathrm{O}$ e $130 \mathrm{~kg} \mathrm{ha}^{-1}$ de N. A aplicação dos fertilizantes deu-se em dois momentos, sendo o primeiro com as plantas em estádio fenológico $\mathrm{V}_{4}$ com aporte total de fósforo e o potássio, mais $40 \%$ do nitrogênio, e o segundo no início da diferenciação do primórdio floral com $60 \%$ do nitrogênio.

A semeadura do ensaio foi realizada no dia 23 de setembro de 2017, a cultivar utilizada foi a SCS 121 $\mathrm{CL}$ na densidade de semeadura de $120 \mathrm{~kg} \mathrm{ha}^{-1}$. Todas as aplicações de herbicidas foram realizadas com o auxílio de um pulverizador costal pressurizado a $\mathrm{CO}_{2}$, munido de barra com três bicos espaçados a $0,5 \mathrm{~m}$, contento pontas do modelo TT 110 015, com pressão de trabalho de $207 \mathrm{kPa}$, velocidade de deslocamento de $1,0 \mathrm{~m} \mathrm{~s}^{-1}$ e altura em relação ao alvo de $0,5 \mathrm{~m}$. Essa combinação proporcionou uma taxa de aplicação equivalente a $150 \mathrm{~L} \mathrm{ha}^{-1}$. As condições climáticas na primeira aplicação eram: céu encoberto, umidade relativa do ar de $72 \%$ e $20,9 \stackrel{\circ}{ } \mathrm{C}$ de temperatura do ar e velocidade do vento oscilando de 0,5 a $2,5 \mathrm{~km} \mathrm{~h}^{-1}$. $\mathrm{Na}$ segunda aplicação o céu estava encoberto, a umidade relativa do ar de $63 \%$ e $28 \stackrel{\circ}{\circ}$ de temperatura do ar e velocidade do vento oscilando de 1,5 a $4,0 \mathrm{~km} \mathrm{~h}^{-1}$. As plantas daninhas que emergiram na área 
experimental foram retiradas manualmente.

Os tratos culturais foram realizados conforme o padrão comercial, sendo duas aplicações do inseticida [alfa-cypermethrin + acetamiprid] para controle de infestações de percevejos e duas aplicações de fungicidas para controle do complexo de manchas foliares com epoxiconazol + kresoxym-methyl (1 $1^{\text {a }}$ aplicação em $R_{1}$ e $2^{\underline{a}}$ após 15 dias).

Antes da embebição das sementes, coletou-se amostras com e sem tratamento de sementes para realização do teste de germinação, que foi realizado em caixas do tipo gerbox e papel germitest umedecido, com 25 sementes e quatro repetições. Os gerbox foram acondicionados em germinadores com temperatura controlada de $30^{\circ} \mathrm{C}$, sendo realizada a primeira contagem aos cinco dias e a contagem final aos 14 dias.

Avaliou-se a fitointoxicação dos tratamentos aos 7, 14 e 21 dias após a segunda aplicação dos herbicidas (DASA). Nesta avaliação utilizou-se uma escala visual em que a nota $0 \%$ representa a ausência de sintomas de fitointoxicação e a nota $100 \%$ a morte da planta.

Aos 21 DAS avaliou-se o número de plantas por metro quadrado, contando o número de plantas emergidas em $1 \mathrm{~m}^{2}$, e o número de perfilhos por planta, avaliado em cinco plantas por parcela. Ao final do ciclo, no estádio $R_{9}$, foi realizada manualmente colheita e degrane, aferida a umidade de cada amostra $e$ padronizada para $13 \%$. As variáveis avaliadas foram: número de panículas por metro quadrado, número de grãos por panícula, massa da panícula, esterilidade de espiguetas, massa de mil grãos e produtividade de grãos. Os componentes de produtividade foram avaliados em cinco plantas por parcela e a produtividade pela colheita da área útil.

Os dados foram submetidos à análise de variância e as médias foram comparadas pelo teste de comparação múltipla de médias de Tukey. O nível de significância adotado em todas as análises foi de $5 \%$ $(p<0,05)$.

\section{RESULTADOS E DISCUSSÃO}

O tratamento de sementes proporcionou percentual de germinação semelhante à testemunha tanto na contagem inicial ( 5 dias), como na final (14 dias). O desvio padrão também foi ligeiramente menor onde se utilizou o tratamento de sementes, indicando homogeneidade de germinação (Figura 1). Este resultado deve-se ao controle dos patógenos, já que não foi observada incidência de fungos apenas nas sementes tratadas.

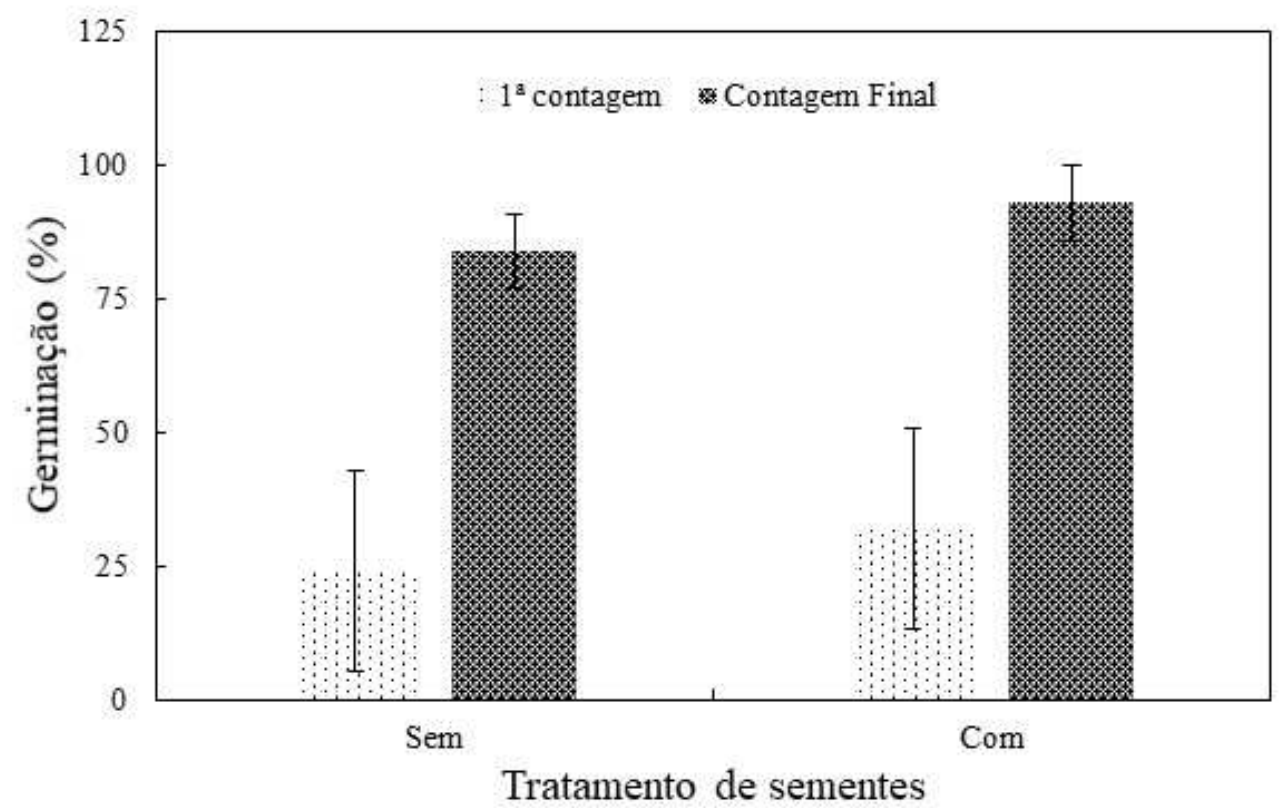

Figura 1. Germinação das sementes de arroz (\%) utilizadas no experimento na avaliação de primeira contagem e contagem final. Taió, SC, 2017/2018.

Figure 1. Rice seed germination (\%) sowed in the experiment in the assessment of first count and final count. Taió, SC, 2017/2018.

Os tratamentos herbicidas promoveram baixos níveis de fitointoxicação visual nas plantas de arroz aos 7 DASA, com valor máximo de $23,8 \%$ (Tabela 1). A mistura tripla de [imazapyr + imazapic] + bentazon + saflufenacil foi o tratamento com maior intoxicação, diferindo significativamente da testemunha não tratada e da mistura dupla do [imazapyr + imazapic] + bentazon. Independente do tratamento de sementes, quando 
se realizou a prática da mistura em tanque de herbicidas observou-se aumento na fitointoxicação. Em média, ela foi menor onde se realizou o tratamento das sementes, com maior diferença na mistura tripla, onde a fitointoxicação foi $5 \%$ menor com o tratamento de sementes (Tabela 1).

Tabela 1. Fitointoxicação dos tratamentos (\%), aos 7 e 14 dias após a segunda aplicação (DASA), em função do tratamento de sementes e da aplicação de herbicidas em pós-emergência. Taió, SC, 2017/2018.

Table 1. Treatment phytointoxication (\%), at 7 and 14 days after the second application (DASA), in function of seed treatment and post-application herbicides. Taió, SC, 2017/2018.

\begin{tabular}{|c|c|c|}
\hline \multicolumn{3}{|c|}{ Fitointoxicação (\%) aos 7 DASA } \\
\hline \multirow{2}{*}{ Herbicidas } & \multicolumn{2}{|c|}{ Tratamento de sementes } \\
\hline & Sem & Com \\
\hline $\mathrm{T}$ & $0,0 \mathrm{Ac}$ & $0,0 \mathrm{Ac}$ \\
\hline $\mathrm{IM} / \mathrm{IM}+\mathrm{B}$ & $16,3 \mathrm{Ab}$ & $12,5 \mathrm{Ab}$ \\
\hline $\mathrm{IM} / \mathrm{IM}+\mathrm{S}$ & $20,0 \mathrm{Aab}$ & $16,8 \mathrm{Aab}$ \\
\hline $\mathrm{IM} / \mathrm{IM}+\mathrm{B}+\mathrm{S}$ & $23,8 \mathrm{Aa}$ & $17,8 \mathrm{Ba}$ \\
\hline Média & $15,0 \mathrm{~A}$ & $12,0 \mathrm{~B}$ \\
\hline \multirow[t]{2}{*}{ CV (\%) } & \multicolumn{2}{|c|}{20,6} \\
\hline & \multicolumn{2}{|c|}{ Fitointoxicação (\%) aos 14 DASA } \\
\hline \multirow{2}{*}{ Herbicidas } & \multicolumn{2}{|c|}{ Tratamento de sementes } \\
\hline & Sem & Com \\
\hline $\mathrm{T}$ & $0,0 \mathrm{Ac}$ & $0,0 \mathrm{Ab}$ \\
\hline $\mathrm{IM} / \mathrm{IM}+\mathrm{B}$ & $4,5 \mathrm{Ab}$ & $2,0 \mathrm{Ab}$ \\
\hline $\mathrm{IM} / \mathrm{IM}+\mathrm{S}$ & $7,5 \mathrm{Ab}$ & $7,8 \mathrm{Aa}$ \\
\hline $\mathrm{IM} / \mathrm{IM}+\mathrm{B}+\mathrm{S}$ & $12,3 \mathrm{Aa}$ & $9,3 \mathrm{Ba}$ \\
\hline Média & $6,0 \mathrm{~A}$ & $4,8 \mathrm{~A}$ \\
\hline CV (\%) & \multicolumn{2}{|c|}{35,5} \\
\hline
\end{tabular}

Aos 14 DASA, os níveis de fitointoxicação reduziram significativamente, com intoxicação máxima de $12,3 \%$ (Tabela 1). Quando as sementes não receberam tratamento, todos os herbicidas promoveram intoxicação superior a testemunha não tratada, sendo a mistura tripla $(\mathrm{IM}+\mathrm{B}+\mathrm{S})$ a que proporcionou a maior intoxicação. Resultados semelhantes foram descritos por MOURA et al. (2016), com intoxicação de 11,67\% aos 14 dias após a aplicação de saflufenacil na dose de $112,5 \mathrm{~g} \mathrm{ha}^{-1}$. Esses resultados não se repetiram para o grupo com tratamento de sementes, pois a mistura de [imazapyr + imazapic] + bentazon teve desempenho semelhante à testemunha e não se observou diferença significativa entre a mistura de [imazapyr + imazapic] + saflufenacil e [imazapyr + imazapic] + bentazon + saflufenacil. A fitointoxicação foi inferior com o tratamento das sementes apenas na mistura tripla de herbicidas (Tabela 1).

Aos 21 DASA as plantas não apresentaram qualquer sintoma visual de fitointoxicação (dados não apresentados). Resultados semelhantes foram apresentados por CAMARGO et al. (2011), que relataram fitointoxicação inicial variando de 6 a 26\%, dependendo da dose de saflufenacil aplicada em pósemergência, com redução dos níveis para valores próximos a zero a partir de 12 dias após a aplicação. Além disso, sabe-se que a associação de saflufenacil aumenta a absorção e a translocação das imidazolinonas em Oryza spp., o que contribui com o rápido aparecimento dos sintomas (CAMARGO et al. 2012).

Mesmo com os baixos níveis de fitointoxicação pode-se comprovar que a hipótese inicial estava correta, já que os níveis de intoxicação foram menores quando utilizou-se a pyraclostrobin via tratamento de semente. Provavelmente esses resultados estão associados aos efeitos positivos da pyraclostrobin sobre as enzimas antioxidantes que auxiliam na detoxificação de herbicidas (KANUNGO \& JOSHI 2014).

Em nenhum dos tratamentos herbicidas houve diferença significativa no estande de plantas aos 21 DASA (Tabela 2). O mesmo ocorreu para o fator tratamento de sementes, que apesar da média superior, não se observou efeito significativo $(p>0,05)$. Certamente o baixo nível de fitointoxicação causado pela aplicação de herbicidas contribuiu com estes resultados, já que os sintomas observados foram transitórios e não promoveram a morte das plantas. 
Tabela 2. Estande de plantas (plantas $\mathrm{m}^{-2}$ ) em função do tratamento de sementes e da aplicação de herbicidas em pós-emergência. Taió, SC, 2017/2018.

Table 2. Plants stand (plants $\mathrm{m}^{-2}$ ) in function of seed treatment and post-application herbicides. Taió, SC, 2017/2018.

\begin{tabular}{lll}
\hline & \multicolumn{2}{c}{ Estande $\left(\right.$ plantas $\mathrm{m}^{-2}$ ) } \\
\cline { 2 - 3 } Herbicidas & \multicolumn{2}{c}{ Tratamento de sementes } \\
\hline $\mathrm{T}$ & $261^{\mathrm{ns}}$ & Com \\
$\mathrm{IM} / \mathrm{IM}+\mathrm{B}$ & 263 & 254 \\
$\mathrm{IM} / \mathrm{IM}+\mathrm{S}$ & 319 & 286 \\
$\mathrm{IM} / \mathrm{IM}+\mathrm{B}+\mathrm{S}$ & 246 & 326 \\
\hline Média & 272 & 238 \\
\hline CV $(\%)$ & 31,2 & 276 \\
\hline
\end{tabular}

T = Testemunha sem herbicida, IM = [imazapyr + imazapic] $\left(K_{i f i}{ }^{\Theta} 140 \mathrm{~g} \mathrm{ha}^{-1}\right), \mathrm{B}=$ bentazon (Basagran $\left.600^{\circledast} 2 \mathrm{~L} \mathrm{ha}^{-1}\right) \mathrm{e}$ $\mathrm{S}=$ saflufenacil $\left(\right.$ Heat $\left.^{\circledR} 100 \mathrm{~g} \mathrm{ha}^{-1}\right) .{ }^{\text {ns }}=$ não significativo $(\mathrm{p}>0,05)$.

Os fatores avaliados apresentaram interação significativa para a variável número de perfilhos por planta, sendo que o tratamento de sementes apresentou número de perfilhos superior para a mistura tripla de [imazapyr + imazapic] + bentazon + saflufenacil (Tabela 3). Esse resultado é importante para a cultura do arroz irrigado, pois o número de perfilhos por plantas é um componente de rendimento, com participação direta no número de panículas por $\mathrm{m}^{2}$. Em média, o número de perfilhos por plantas do grupo que recebeu tratamento de semente foi superior ao não tratado, reforçando a relação positiva desta prática com o crescimento inicial do arroz irrigado.

Tabela 3. Número de perfilhos por planta ( $\left.n^{\circ}\right)$ em função do tratamento de sementes e da aplicação de herbicidas em pós-emergência. Taió, SC, 2017/2018.

Table 3. Number of tillers per plant (number) in function of seed treatment and post-application herbicides. Taió, SC, 2017/2018.

\begin{tabular}{|c|c|c|}
\hline \multicolumn{3}{|c|}{ Perfilhos por plantas ( $\mathrm{n}^{\circ}$ ) } \\
\hline \multirow{2}{*}{ Herbicidas } & \multirow{2}{*}{\multicolumn{2}{|c|}{ Tratamento de sementes }} \\
\hline & & \\
\hline $\mathrm{T}$ & 4,3 Aa & 4,9 Aa \\
\hline $\mathrm{IM} / \mathrm{IM}+\mathrm{B}$ & 4,4 Aa & 4,9 Aa \\
\hline $\mathrm{IM} / \mathrm{IM}+\mathrm{S}$ & 4,8 Aa & $5,1 \mathrm{Aa}$ \\
\hline $\mathrm{IM} / \mathrm{IM}+\mathrm{B}+\mathrm{S}$ & $4,3 \mathrm{Ba}$ & $5,4 \mathrm{Aa}$ \\
\hline Média & 4,4 B & $5,1 \mathrm{~A}$ \\
\hline CV (\%) & 11,3 & \\
\hline
\end{tabular}

A esterilidade de espiguetas das panículas de arroz irrigado, não foi afetada pelos fatores avaliados (Tabela 4). Estes resultados já eram esperados já que todo experimento sofreu as mesmas influências climáticas e fitossanitárias, os quais são os principais responsáveis por causar danos significativos nas panículas. Além disso, a cultivar SCS $121 \mathrm{CL}$ apresentou na safra 2017/2018 boa tolerância à brusone (Pyricularia oryzae) que é a principal causadora da esterilidade de espiguetas nas plantas de arroz irrigado.

Para os componentes de rendimento: número de panículas por metro quadrado (Tabela 5), número de grãos por panícula (Tabela 6), massa média da panícula (Tabela 7) e massa de mil grãos (Tabela 8), não se observou influência significativa entre os fatores avaliados $(p>0,05)$. Entretanto, a superioridade numérica do grupo que recebeu tratamento de sementes se repetiu em todos os componentes.

O resultado da produtividade de grãos seguiu o mesmo padrão descrito para os componentes de rendimento (Tabela 9). Contudo, destaca-se que o grupo com tratamento de sementes apresentou produtividade média de $820 \mathrm{~kg} \mathrm{ha}^{-1}$ superior ao grupo sem tratamento de sementes, sendo a probabilidade para significância de $94,9 \%(p=0,051)$. Acredita-se que dois fatores contribuíram para este resultado, primeiro a menor fitointoxicação dos herbicidas e segundo pela resposta positiva do tratamento de semente sobre o número de perfilhos por planta. 
Tabela 4. Esterilidade de espiguetas (\%) em função do tratamento de sementes e da aplicação de herbicidas em pós-emergência. Taió, SC, 2017/2018.

Table 4. Spikelet sterility (\%) in function of seed treatment and post-application herbicides. Taió, SC, 2017/2018.

\begin{tabular}{llr}
\hline & \multicolumn{2}{c}{ Esterilidade de espiguetas (\%) } \\
\cline { 2 - 3 } Herbicidas & \multicolumn{2}{c}{ Tratamento de sementes } \\
\hline T & Sem & Com \\
IM/IM+B & $10,7^{\text {ns }}$ & 11,5 \\
IM/M+S & 11,2 & 11,9 \\
IM/IM+B+S & 13,9 & 11,0 \\
\hline Média & 11,5 & 9,2 \\
\hline CV $(\%)$ & 11,8 & 11,0 \\
\hline
\end{tabular}

$\overline{\mathrm{T}}=$ Testemunha sem herbicida, IM = [imazapyr + imazapic] $\left(\right.$ Kifix $\left.^{\Theta} 140 \mathrm{~g} \mathrm{ha}^{-1}\right), \mathrm{B}=$ bentazon (Basagran $\left.600^{\circledast} 2 \mathrm{~L} \mathrm{ha}^{-1}\right) \mathrm{e}$ $\mathrm{S}=$ saflufenacil $\left(\mathrm{Heat}^{\circledR} 100 \mathrm{~g} \mathrm{ha}^{-1}\right) \cdot{ }^{\text {ns }}=$ não significativo $(\mathrm{p}>0,05)$.

Tabela 5. Número de panículas por metro quadrado ( $\left.\mathrm{n}^{\circ}\right)$ em função do tratamento de sementes e da aplicação de herbicidas em pós-emergência. Taió, SC, 2017/2018.

Table 5. Number of panicles per square meter (number) in function of seed treatment and post-application herbicides. Taió, SC, 2017/2018.

\begin{tabular}{lll}
\hline & \multicolumn{2}{c}{ Panícula por $\mathrm{m}^{2}\left(\mathrm{n}^{\circ}\right)$} \\
\hline \multirow{2}{*}{ Herbicidas } & Tratamento de sementes \\
\cline { 2 - 3 } & Sem & Com \\
\hline $\mathrm{T}$ & $448^{\mathrm{ns}}$ & 456 \\
$\mathrm{IM} / \mathrm{M}+\mathrm{B}$ & 452 & 510 \\
$\mathrm{IM} / \mathrm{M}+\mathrm{S}$ & 454 & 448 \\
$\mathrm{IM} / \mathrm{M}+\mathrm{B}+\mathrm{S}$ & 454 & 493 \\
\hline Média & 452 & 477 \\
\hline CV $(\%)$ & 9,9 & \\
\hline
\end{tabular}

$\mathrm{T}=$ Testemunha sem herbicida, IM = [imazapyr + imazapic] $\left(\right.$ Kifix $\left.^{\Theta} 140 \mathrm{~g} \mathrm{ha}^{-1}\right), \mathrm{B}=$ bentazon (Basagran $\left.600^{\Theta} 2 \mathrm{~L} \mathrm{ha}^{-1}\right) \mathrm{e}$

$\mathrm{S}=$ saflufenacil $\left(\right.$ Heat $\left.^{\Theta} 100 \mathrm{~g} \mathrm{ha}^{-1}\right) .{ }^{\text {ns }}=$ não significativo $(p>0,05)$.

Tabela 6. Número de grãos por panícula (nº) em função do tratamento de sementes e da aplicação de herbicidas em pós-emergência. Taió, SC, 2017/2018.

Table 6. Number of grain per panicle (number) in function of seed treatment and post-application herbicides. Taió, SC, 2017/2018.

\begin{tabular}{|c|c|c|}
\hline \multicolumn{3}{|c|}{ Grãos panícula $^{-1}\left(\mathrm{n}^{\circ}\right)$} \\
\hline \multirow{2}{*}{ Herbicidas } & \multicolumn{2}{|c|}{ Tratamento de sementes } \\
\hline & Sem & Com \\
\hline$T$ & $81,0^{\text {ns }}$ & 83,0 \\
\hline $\mathrm{IM} / \mathrm{IM}+\mathrm{B}$ & 88,5 & 86,0 \\
\hline $\mathrm{IM} / \mathrm{IM}+\mathrm{S}$ & 85,5 & 86,0 \\
\hline $\mathrm{IM} / \mathrm{IM}+\mathrm{B}+\mathrm{S}$ & 77,5 & 81,5 \\
\hline Média & 83,0 & 84,0 \\
\hline
\end{tabular}

$\overline{\mathrm{T}}=$ Testemunha sem herbicida, IM = [imazapyr + imazapic] $\left(\right.$ Kifix $\left.^{\circledR} 140 \mathrm{~g} \mathrm{ha}^{-1}\right), \mathrm{B}=$ bentazon (Basagran $\left.600^{\circledR} 2 \mathrm{~L} \mathrm{ha}^{-1}\right) \mathrm{e}$ $\mathrm{S}=$ saflufenacil $\left(\right.$ Heat $\left.^{\circledR} 100 \mathrm{~g} \mathrm{ha}^{-1}\right) .{ }^{\text {ns }}=$ não significativo $(p>0,05)$.

A mistura de fipronil + piraclostrobin + thiophanate-methyl em tratamento de sementes resultou em maior produtividade de grãos de arroz em sistema de terras altas, em sistema de plantio direto e convencional, com acréscimos de $286 \mathrm{~kg} \mathrm{ha}^{-1}$ e $166 \mathrm{~kg} \mathrm{ha}^{-1}$, respectivamente (PINHEIRO et al. 2016). Em soja foi observado incremento no rendimento de grãos com o uso da mistura fipronil + pyraclostrobin + thiophanate-methyl na ordem de $57,8 \%$ comparado a testemunha sem tratamento de sementes (BALARDIN et al. 2011). Uma possível interação positiva da estrobilurina presente na mistura pode ter contribuído para o aumento no rendimento, em plantas de Arabidopsis thaliana observou-se que a aplicação de kresoxim- 
methyl resultou em folhas maiores devido ao aumento no número de células, além disso análises complementares demostraram maior expressão de genes relacionados a homeostase redox, metabolismo do ferro e transporte de açúcares nas plantas tratadas com a estrobilurina (VAN DINGENEN et al. 2017).

Tabela 7. Massa da panícula ( $\mathrm{g}$ ) em função do tratamento de sementes e da aplicação de herbicidas em pós-emergência. Taió, SC, 2017/2018.

Table 7. Panicle weight $(g)$ in function of seed treatment and post-application herbicides. Taió, SC, $2017 / 2018$.

\begin{tabular}{|c|c|c|}
\hline \multicolumn{3}{|c|}{ Massa da panícula (g) } \\
\hline \multirow{2}{*}{ Herbicidas } & \multicolumn{2}{|c|}{ Tratamento de sementes } \\
\hline & Sem & Com \\
\hline$T$ & $2,3^{\mathrm{ns}}$ & 2,4 \\
\hline $\mathrm{IM} / \mathrm{IM}+\mathrm{B}$ & 2,4 & 2,4 \\
\hline $\mathrm{IM} / \mathrm{IM}+\mathrm{S}$ & 2,3 & 2,4 \\
\hline $\mathrm{IM} / \mathrm{IM}+\mathrm{B}+\mathrm{S}$ & 2,2 & 2,3 \\
\hline Média & 2,3 & 2,4 \\
\hline CV (\%) & 12,9 & \\
\hline
\end{tabular}

Tabela 8. Massa de mil grãos (g) em função do tratamento de sementes e da aplicação de herbicidas em pós-emergência. Taió, SC, 2017/2018.

Table 8. Thousand grains weight (g) in function of seed treatment and post-application herbicides. Taió, SC, $2017 / 2018$.

\begin{tabular}{|c|c|c|}
\hline \multicolumn{3}{|c|}{ Massa de mil grãos (g) } \\
\hline \multirow{2}{*}{ Herbicidas } & \multicolumn{2}{|c|}{ Tratamento de sementes } \\
\hline & Sem & Com \\
\hline $\mathrm{T}$ & $31,3^{\text {ns }}$ & 32,9 \\
\hline $\mathrm{IM} / \mathrm{IM}+\mathrm{B}$ & 31,1 & 31,6 \\
\hline $\mathrm{IM} / \mathrm{IM}+\mathrm{S}$ & 31,3 & 32,1 \\
\hline $\mathrm{IM} / \mathrm{IM}+\mathrm{B}+\mathrm{S}$ & 31,7 & 31,7 \\
\hline Média & 31,3 & 32,1 \\
\hline CV (\%) & 3,7 & \\
\hline
\end{tabular}

Tabela 9. Produtividade de grãos de arroz em casca $\left(\mathrm{kg} \mathrm{ha}^{-1}\right)$ em função do tratamento de sementes e da aplicação de herbicidas em pós-emergência. Taió, SC, 2017/2018.

Table 9. Rice grain yield $\left(\mathrm{kg} \mathrm{ha}^{-1}\right)$ in function of seed treatment and post-application herbicides. Taió, SC, 2017/2018.

\begin{tabular}{|c|c|c|}
\hline \multicolumn{3}{|c|}{ Produtividade de grãos $\left(\mathrm{kg} \mathrm{ha}^{-1}\right)$} \\
\hline \multirow{2}{*}{ Herbicidas } & \multicolumn{2}{|c|}{ Tratamento de sementes } \\
\hline & Sem & Com \\
\hline $\mathrm{T}$ & $8526^{\text {ns }}$ & 9956 \\
\hline $\mathrm{IM} / \mathrm{IM}+\mathrm{B}$ & 8568 & 9453 \\
\hline $\mathrm{IM} / \mathrm{IM}+\mathrm{S}$ & 8937 & 9896 \\
\hline $\mathrm{IM} / \mathrm{IM}+\mathrm{B}+\mathrm{S}$ & 9249 & 9555 \\
\hline Média & $8895 \mathrm{~A}$ & $9715 A^{*}$ \\
\hline CV (\%) & 12,0 & \\
\hline
\end{tabular}

Esses resultados indicam que a fitointoxicação inicial promovida pelas misturas de herbicidas não foram suficientemente intensas para prejudicar a produtividade da cultura. De certa forma, esses resultados 
já eram esperados, já que os níveis de fitointoxicação foram baixos desde a avaliação de 7 DASA. Resultados semelhantes foram relatados por BONOW et al. (2015) que aplicaram doses de até $147 \mathrm{~g} \mathrm{ha}^{-1}$ de saflufenacil, na cultivar BRS Pampa, e não obtiveram decréscimo no rendimento de grãos. CAMARGO et al. (2011) também não relataram prejuízos à produtividade de arroz irrigado com aplicação de saflufenacil em pós-emergência em doses de até $50 \mathrm{~g} \mathrm{ha}^{-1}$, em dois anos agrícolas.

Destaca-se que pesquisas sobre tratamento de sementes de arroz em sistema pré-germinado são escassas, sendo assim necessário o desenvolvimento de pesquisas mais abrangentes. Apesar de 0 planejamento experimental ter sido voltado à interação com herbicidas, houve um resultado muito próximo da significância para produtividade de grãos e que reforçou a tendência observada nos principais componentes de produtividade. Este resultado positivo pode ter sido causado pela estrobilurina. Em Arabidopsis thaliana a aplicação de kresoxim-methyl resultou em aumento da área foliar (VAN DINGENEN et al. 2017), fungicida do grupo das estrobilurinas. A aplicação da pyraclostrobin proporcionou efeitos positivos nos mecanismos antioxidativos e carboxilativos refletindo no aumento da produtividade de grãos na cultura do feijão (JADOSKI et al. 2015). FAGAN et al. (2010), avaliando os efeitos da pyraclostrobin nas variáveis fisiológicas da cultura da soja, encontraram efeitos positivos na aplicação da pyraclostrobin na carboxilação, obtendo aumento de 7 e $8 \%$ na produtividade de grãos.

\section{CONCLUSÃO}

O uso do tratamento de sementes com pyraclostrobin + thiophanate-methyl + fipronil proporcionou a redução na fitointoxicação causada pela aplicação da mistura tripla [imazapyr + imazapic] + bentazon + saflufenacil em arroz irrigado cultivado em sistema pré-germinado.

Os fatores tratamento de sementes e herbicidas aplicados em pós-emergência não afetaram os componentes de rendimento e a produtividade de grãos do arroz irrigado.

\section{REFERÊNCIAS}

BALARDIN RS et al. 2011. Tratamento de sementes com fungicidas e inseticidas como redutores dos efeitos do estresse hídrico em plantas de soja. Ciência Rural 41: 1120-1126.

BERTUCCI MB et al. 2019. Efficacy of fall-applied residual herbicides on weedy rice control in rice (Oryza sativa L.). Weed Technology 33: 441-447.

CAMARGO ER et al. 2011. Rice tolerance to saflufenacil in clomazone weed control program. International Journal of Agronomy. Article ID 402461. 8p.

CAMARGO ER et al. 2012. Interaction between saflufenacil and imazethapyr in red rice (Oryza spp.) and hemp sesbania (Sesbania exaltata) as affected by light intensity. Pest Management Science 68: 1010-1018.

COUNCE PA et al. 2000. A uniform, objective, and adaptative system for expressing rice development. Crop Science 40: 436-443.

DAYAN FE \& WATSON SB. 2011. Plant cell membrane as a marker for light-dependent and light-independent herbicide mechanisms of action. Pesticide Biochemistry and Physiology 101: 182-190.

BONOW JFL et al. 2015. Seletividade do herbicida saflufenacil na cultura do arroz irrigado. In: IX Congresso Brasileiro do Arroz Irrigado. Anais... Pelotas: SOSBAI. p.896-899.

FAGAN EB et al. 2010. Efeito da aplicação de Piraclostrobina na taxa fotossintética, respiração, atividade da enzima nitrato redutase e produtividade de grãos de soja. Bragantia 69: 771-777.

FAO. 2019. FOOD AND AGRICULTURE ORGANIZATION OF UNITED NATIONS. Faostat - Crops. Disponível em: http://www.fao.org/faostat/en/\#data/QC. Acesso em: 04 set. 2019.

GAO S et al. 2019. Protective responses induced by chiral 3-dichloroacetyl oxazolidine safeners in maize (Zea mays L.) and the detoxification mechanism. Molecules 24: 3060.

GEOFFROY $L$ et al. 2002. Effect of oxyfluorfen and diuron alone and in mixture on antioxidative enzymes of Scenedesmus obliquus. Pesticide Biochemistry and Physiology 72: 178-185.

GILL SS \& TUTEJA N. 2010. Reactive oxygen species and antioxidant machinery in abiotic stress tolerance in crop plants. Plant Physiology Biochemistry 48: 909-930.

GROSSMANN K et al. 2011. Saflufenacil (KixorTM): biokinetic properties and mechanism of selectivity of a new protoporphyrinogen IX oxidase inhibiting herbicide. Weed Science 59: 290-298.

HAVERROTH EJ et al. 2017. Efeito da associação de herbicidas para o controle de Sagittaria montevidensis em arroz de cultivo pré-germinado. In: Anais do X Congresso Brasileiro do Arroz Irrigado. Gramado: SOSBAI.

JABS T. 2004. Can strobilurins still deliver? Crop Protection 17: 19-20.

LIEBL RA et al. 2008. BAS 800H: A new herbicide for preplant burndown and preemergence dicot weed control. Weed Science Society of America 48: 120.

JADOSKI CJ et al. 2015. Ação fisiológica da piraclostrobina na assimilação de $\mathrm{CO}_{2}$ e na atividade de enzimas antioxidantes em plantas de feijão em diferentes tensões de água no solo. Irriga 20: 319-333.

KANUNGO M \& JOSHI J. 2014. Impact of pyraclostrobin (F-500) on crop plants. Plant Science Today 3: $174-178$.

KNEZEVIC SZ et al. 2010. Application timing and adjuvant type affected saflufenacil efficacy on selected broadleaf

Rev. Ciênc. Agrovet., Lages, SC, Brasil (ISSN 2238-1171) 
weeds. Crop Protection 29: 94-99.

KNEZEVIC SZ et al. 2009. Adjuvants influenced saflufenacil efficacy on fall-emerging weeds. Weed Technology 23: 340345.

KÖEHLE H et al. 2003. Physiological effects of the strobilurin fungicide F 500 on plants. In: DEHNE HW et al. Modern Fungicides and Antifungal Compounds. Germany: Spring. p.61-74.

KRUSE ND et al. 2006. Estresse oxidativo em girassol (Helianthus annuus) indica sinergismo para a mistura dos herbicidas metribuzin e clomazone. Planta Daninha 24: 379-390.

LIMA AS et al. 2009. Efeito fisiológico de funcigida pyraclostrobin e tratamento de sementes na cultura do milho. Pesquisa Aplicada \& Agrotecnologia 2: 113-120.

MATZENBACHER FO et al. 2014. Environmental and physiological factors that affect the efficacy of herbicides that inhibit the enzyme protoporphyrinogen oxidase: a literature review. Planta Daninha 32: 457-463.

MEROTTO JUNIOR A et al. 2010. Isolamento do gene ALS e investigação do mecanismo de resistência a herbicidas em Sagittaria montevidensis. Ciência Rural 40: 2381-2384.

MOURA DS et al. 2015. Multiple resistance of Sagittaria montevidensis biotypes to acetolactate synthase and photosystem II inhibiting herbicides. Planta Daninha 33: 779-786.

MOURA DS et al. 2016. Multiple resistant biotypes of Sagittaria montevidensis to inhibiting acetolactate synthase and photosystem II herbicides. Revista Brasileira de Herbicidas 15: 148-156.

PINHEIRO V et al. 2016. Seed treatment, soil compaction and nitrogen management affect upland rice. Pesquisa Agropecuária Tropical 46: 72-79.

SOLTANI N et al. 2009. Response of corn to preemergence and postemergence applications of saflufenacil. Weed Technology 23: 331-334.

SOSBAI. 2016. SOCIEDADE SUL-BRASILEIRA DE ARROZ IRRIGADO. XXXI Reunião Técnica da Cultura Arroz Irrigado: recomendações técnicas da pesquisa para o Sul do Brasil. Santa Maria: SOSBAI. 197p.

TAKANO HK et al. 2019. Reactive oxygen species trigger the fast action of glufosinate. Planta 249: 1837-1849.

VAN DINGENEN $J$ et al. 2017. Strobilurins as growth-promoting compounds: how stroby regulates Arabidopsis leaf growth. Plant, Cell and Environment 40: 1748-1760.

VENANCIO WS et al. 2004. Efeitos fisiológicos de fungicidas sobre plantas. Revisão Anual de Patologia de Plantas 12 : 317-341. 